\section{Association of Geoscientists for International Development}

SIR,-Your timely editorial "After geodynamics, what?" (15 February, page 503) was read with interest.

From the tone of the editorial, however, it appears that you have not yet become familiar with the Association of Geoscientists for International Development (AGID). Originally conceived at a symposium on the role of the geosciences in international development at the 1972 International Geological Congress in Montreal, AGID has grown to a membership of 1,100 geoscientists in 95 countries in its roughly five years of active existence. In this time it has held several symposia and workshops aimed at fostering technology on problems in developing countries, and, more particularly, at increasing the capabilities of developing country geoscience communities. Such topics as geoscience education in developing countries (Australia, 1976), geochemical exploration in the tropics (Zambia, 1977), and mineral exploration in the tropical rain forest (Venezuela, 1977) have been treated in this manner.

Among AGID's several publications are a quarterly newsletter, a directory of university geoscience departments in developing countries, a bibliography of groundwater reports pertaining to LDC's, and a critique of geoscience-related development aid.

Though it has kept a low profile in many 'developed' nations, AGID is well known in its area of emphasis from the abovementioned workshops and publications, for its surplus literature exchange (enabling organisations with insufficient foreign exchange for purchasing geological publications to obtain such materials that were donated as surplus by others), its appropriate technology referral and other services. and by the activities of its members.

AGID has sometimes been considered mainly as a means of technology transfer. But technology transfer is not AGID's only purpose, nor, certainly, is this an activity unique to AGID. Perhaps its unique challenge is to overcome the lack of emphasis on, and knowledge of, the peculiar geological environments found in developing countries which by themselves currently have limited resources for attacking these problems individually. Basic problems such as the effects of tropical weathering on geochemical dispersion, and of seasonally fluctuating water tables and surface wetness on geophysical exploration in tropical environments have received almost no aftention; and engineers are of ten still caught designing structures often still caught designing structures will hold a steep slope indefinitely (when the feldspars quickly weather to clay in the humid tropical environment. producing rapid slope failure). For the above ressons the need for an international institute. somewhat similar to the International Centre for Theoretical
Physics at Trieste but located in a tropical environment, is even more critical to the geosciences than to theoretical physics. Although AGID's workshops have attacked some of these problems, the need for a continuous institution directed at improving geoscience capabilities worldwide has been a goal of the Association since its inception. It has just completed an overall plan for such an institute, based on the experiences gained from its workshops and of its members.

The Association has received generous support from the Canadian International Development Agency, the (Canadian) International Development Research Centre, and the governments of Venezuela and Nigeria. Modest contributions have come from other sources, such as the Commonwealth Foundation. Nevertheless, AGID's accomplishments have been achieved on a shoestring budget.

From this you can see that the "secretariat" that you are seeking already exists. It has an advantagc over attempts to organise such an effort from other existing institutions in that it is already in existence solely to develop the geoscience community where it most needs development. With its broad international base and its headquarters in Caracas it is less likely to become misdirected in its efforts than might a newly created secretariat in Europe or North America.

AGID heartily welcomes partners in its activities. People interested in its goals. as well as financial support are solicited. It is also interested in assisting in ongoing or planned projects, should such assistance be desired. and consistent with its goals. Correspondence can be addressed to $\operatorname{Dr} A$. Bellizzia, Secretary. Association of Geoscientists for International Development, Ministerio de Minas and Hidrocarburos. Torre Norte Piso 19. Centro Simon Bolivar.

Caracas, Venezuela. Yours faithfully. David Hastings

Department of Geology and Geological Engineering. Michigan Technological University, Michigan, USA.

\section{Nigeria needs scientific leaders}

SIR,.-I was interested in Lynette Hamblin's report of Professor Fkong's speech at a recent UNESCO symposium (18 January, page 168 ), and particularly that she considers lack of scientific leadership to be the principal reason for the low scientific output.

At the time when I left the University of Ibadan, I felt that the leadership of that university, in organic chemistry at least, was in good hands with Professor Ekong; but within a very short while he himself had left to take up university administration.
Professor Ekong is not the only leading chemist in Nigeria to have left university teaching and research for administration, in some cases at least quite unwillingly. In Nigeria there are a number of able administrators of one kind and another, whereas there are very few capable scientific leaders, and I question whether the move of scientists into administration is really beneficial, whatever may be the case in more developed countries.

$$
\text { Yours faithfully. }
$$

D. A. H. 'TAYIOR

Department of Chemistry,

University of Natal.

\section{Soviet reactor safety}

SIR,- In your report on Soviet energy (25 January, page 258) Vera Rich reports on the "accident" in BN350, the Russian fast reactor on the Caspian sea. By the use of her words "it is presented as" she seeks to imply that the "accident" was not in the steam generators and that some accident occurred in the reactor core itself. In fact, the full details of this "accident" have been known for many years in the West and have been fully reported in international conferences, for example at the 1978 Bologna Conference (D. S. Yurchenko, et al., Operating Experience with the $B N 350$ Fast Reactor (1972-77); IAEA Symposium on the Design, Construction and Operating Experience with LMFBRs, Bologna, 10-14 April 1978), and many designers have visited $\mathrm{BN} 350$ subsequent to the "accident".

The presentation adopted in the article in Nature seems likely to mislcad and to cast unwarranted doubt both on the integrity of the Soviet physicists concerned, and on the safety of the fast reactor as a power generator. Yours faithfully, R. D. SMITH

UKAEA, Risley, Cheshire, L'K

\section{Intuitive energy figures}

SrR,- P. T. Landsberg (5 April, page 502) expresses the hope that his energy figures carry an intuitive meaning. As a basically illiterate mathematician, may I say that they do. They convey the impression that Mr Landsberg wishes to encourage the belief that natural sources of energy are entirely sufficient for our needs; and that he considers it prudent to publish figures setting out the possible power yield from deserts, without demonstrating the energy investment required to achieve it. I will gladly sacrifice the assistance of $60 \mathrm{~W}$ bulbs per capita even for $10^{\prime \prime}$ joules -in the service of comprehensive energy budgets on all energy projections illustrative or real. alternative or conventional. Yours faithfully,

Pembrokeshire, Wales
DAVII) GrEI:N 